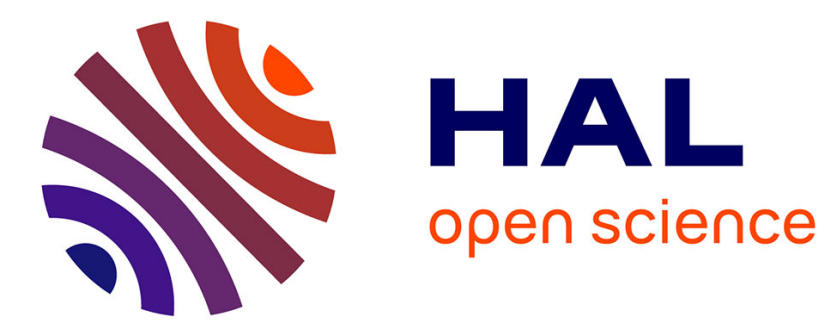

\title{
La valeur nutritive des protéines concentrées de lait
}

S. Poznanski, W. Chojnowski, J. Jakubowski, R. Cichon, W. Bednarski, B.

Wituszynska

\section{To cite this version:}

S. Poznanski, W. Chojnowski, J. Jakubowski, R. Cichon, W. Bednarski, et al.. La valeur nutritive des protéines concentrées de lait. Le Lait, 1976, 56 (558), pp.546-554. hal-00928741

\section{HAL Id: hal-00928741 \\ https://hal.science/hal-00928741}

Submitted on 1 Jan 1976

HAL is a multi-disciplinary open access archive for the deposit and dissemination of scientific research documents, whether they are published or not. The documents may come from teaching and research institutions in France or abroad, or from public or private research centers.
L'archive ouverte pluridisciplinaire HAL, est destinée au dépôt et à la diffusion de documents scientifiques de niveau recherche, publiés ou non, émanant des établissements d'enseignement et de recherche français ou étrangers, des laboratoires publics ou privés. 


\title{
La valeur nutritive des protéines concentrées de lait
}

\author{
par \\ S. POZNANSKI, W. CHOJNOWSKI, J. JAKUBOWSKI, R. CICHON, \\ W. BEDNARSKI* et B. WITUSZYNSKA**
}

On a pris récemment intérêt à faire augmenter l'utilisation des protéines de lait en technologie alimentaire [2, 4]. La demande croissante pour des concentrés divers de protéines a forcé les technologues à mettre au point des préparations de protéines ayant des propriétés physico-chimiques déterminées.

La transformation des protéines de lait, en vue de leur donner des propriétés convenables et la stabilité, entraîne quelquefois des altérations de leur valeur nutritive $[17,18]$. La tâche de l'industrie alimentaire moderne est pourtant de produire la nourriture qui aurait non seulement des qualités sensorielles désirées, mais aussi une valeur nutritive élevée $[16,21]$.

Les plus grandes altérations de la valeur nutritive des protéines sont provoquées par leur traitement aux températures élevées ou par traitement chimique $[7,16,18]$.

Des altérations particulièrement importantes de la valeur biologique des protéines de lait ou des protéines végétales ont été observées au cours de leur chauffage dans une ambiance alcaline [7, 13], ce qui peut avoir lieu au cours de la fabrication des protéines concentrées solubles $[1,3,5]$.

En ce cas, le procédé tecilnologique doit se dérouler de telle manière que les altérations de la valeur biologique soient aussi négligeables que possible, parce que toute altération de la qualité des protéines se reflète lors de l'utilisation réelle de ces protéines par l'organisme vivant.

* Institut du Génie et de la Biotechnologie Alimentaire, Université Agrotechnique d'Olsztyn (Pologne).

** Etablissement de Bromatologie de l'Ecole des Hautes Etudes Médicales à Gdansk. 
Dans notre Institut, une technique a été mise au point pour fabriquer des concentrés de toutes les protéines du lait, sous forme de protéinates de sodium, de calcium, de sodium et calcium et d'ammonium, ainsi que le concentré de protéines de lait n'ayant pas subi le traitement alcalin (Brevet de la République populaire polonaise $n^{\circ} 167094$ [14]). Cette technique permet d'obtenir des protéines concentrées aux propriétés variées [5].

L'objectif de ce travail est de présenter la composition des acides aminés, la teneur en vitamine du groupe B et la valeur biologique des protéines concentrées de lait, en question.

\section{EXPERIMENTATION}

Les concentrés de toutes les protéines de lait ont été fabriqués dans une usine laitière qui disposait d'un séchoir atomiseur, type A, produit par la Compagnie danoise Niro-Atomizer.

L'analyse de la composition en acides aminés des concentrés divers a été effectuée à l'aide d'un analyseur automatique d'acides aminés de la Compagnie Microtechna, Prague (Tchécoslovaquie). L'hydrolyse des protéines a été effectuée par la méthode de Moore et al. [11]. Les vitamines du groupe B étaient déterminées par la méthode microbiologique [20], en se servant de la souche de Lactobacillus fermenti 36 ATCC 9338 pour la vitamine $B_{1}$, de celle de Lactobacillus casei ATCC 7469 pour la vitamine $\mathrm{B}_{2}$, de la levure Saccharomyces carlsbergensis ATCC 9080 pour la vitamine $\mathrm{B}_{6}$ et d'une souche de Lactobacillus arabinosus ATCC 8014 pour la détermination de l'acide nicotinique.

La valeur biologique des protéines dans des concentrés individuels, exprimée par le coefficient d'utilisation de la protéine nette (NPU), était déterminée par le procédé de Miller et Bender [10].

Pour comparaison, de semblables déterminations ont été effectuées en utilisant le caséinate de soude, produit, dans la même laiterie, à partir de la caséine séchée précédemment.

\section{RESULTATS ET DISCUSSION}

La caractéristique des propriétés physico-chimiques et la composition chimique des concentrés en question ont été décrites dans notre publication précédente [5]. L'analyse de la composition en acides aminés, que nous avons présentée dans ce rapport, a démontré que les concentrés que nous avons produits de toutes les protéines de lait, ne différaient pas essentiellement entre eux par leur teneur en acides aminés (tab. 1). Par contre, la comparaison de la compo- 
TABLEAU 1. - Composition en acides aminés de protéines concentrées diverses (en g/16 g N)

\begin{tabular}{|c|c|c|c|c|c|c|c|}
\hline $\mathrm{N}^{\circ}$ & Acides aminés & $\begin{array}{c}\text { Caséinate } \\
\text { de } \\
\text { sodium }\end{array}$ & $\begin{array}{c}\text { Protéinate } \\
\text { de } \\
\text { sodium }\end{array}$ & $\begin{array}{c}\text { Protéinate } \\
\text { de } \\
\text { calcium }\end{array}$ & $\begin{array}{l}\text { Protéinate } \\
\text { de sodium } \\
\text { et calcium }\end{array}$ & $\begin{array}{c}\text { Protéinate } \\
\text { d'ammonium }\end{array}$ & $\begin{array}{l}\text { Concentré de } \\
\text { protéines de lait } \\
\text { n'ayant pas subi } \\
\text { de traitement } \\
\text { alcalin }\end{array}$ \\
\hline $\begin{array}{r}1 \\
2 \\
3 \\
4 \\
5 \\
6 \\
7 \\
8 \\
9 \\
10 \\
11 \\
12 \\
13 \\
14 \\
15 \\
16 \\
17 \\
18\end{array}$ & $\begin{array}{l}\text { Alanine } \\
\text { Arginine } \\
\text { Cystine } \\
\text { Phénylalanine } \\
\text { Glycine } \\
\text { Histidine } \\
\text { Acide aspartique } \\
\text { Acide glutamique } \\
\text { Leucine } \\
\text { Isoleucine } \\
\text { Lysine } \\
\text { Méthionine } \\
\text { Proline } \\
\text { Sérine } \\
\text { Thréonine } \\
\text { Tryptophane } \\
\text { Tyrosine } \\
\text { Valine }\end{array}$ & $\begin{array}{r}3,83 \\
4,69 \\
0,10 \\
4,31 \\
1,25 \\
3,25 \\
7,04 \\
22,30 \\
11,40 \\
5,38 \\
7,08 \\
2,10 \\
9,57 \\
4,12 \\
3,28 \\
1,25 \\
4,14 \\
4,70\end{array}$ & $\begin{array}{r}2,19 \\
4,55 \\
2,09 \\
3,76 \\
1,41 \\
3,75 \\
6,76 \\
23,42 \\
11,50 \\
5,88 \\
9,22 \\
2,87 \\
9,70 \\
3,59 \\
4,64 \\
1,77 \\
3,57 \\
5,09\end{array}$ & $\begin{array}{r}2,20 \\
4,80 \\
1,94 \\
3,96 \\
1,34 \\
3,31 \\
7,32 \\
23,90 \\
10,86 \\
5,20 \\
9,95 \\
2,68 \\
9,55 \\
3,70 \\
3,81 \\
1,68 \\
4,07 \\
4,03\end{array}$ & $\begin{array}{r}2,42 \\
4,75 \\
2,01 \\
3,84 \\
1,46 \\
3,78 \\
6,98 \\
22,54 \\
11,30 \\
5,60 \\
9,47 \\
2,71 \\
9,45 \\
3,63 \\
4,12 \\
1,71 \\
3,84 \\
4,88\end{array}$ & $\begin{array}{r}2,81 \\
5,13 \\
1,97 \\
4,18 \\
1,47 \\
3,86 \\
7,06 \\
22,60 \\
10,74 \\
5,41 \\
9,83 \\
2,60 \\
8,21 \\
3,62 \\
3,96 \\
1,64 \\
3,92 \\
4,58\end{array}$ & $\begin{array}{r}2,76 \\
5,21 \\
2,06 \\
4,15 \\
1,51 \\
4,11 \\
6,92 \\
22,08 \\
10,86 \\
5,38 \\
9,96 \\
2,36 \\
8,14 \\
3,92 \\
4,07 \\
1,76 \\
3,77 \\
4,91\end{array}$ \\
\hline
\end{tabular}


sition en acides aminés de ces concentrés avec celle du caséinate de sodium a révélé des différences assez considérables quant à la teneur en cystine, lysine, méthionine et tryptophane. La teneur du caséinate de sodium s'est montrée moins élevée de 95 p. 100 en cystine, de 27 p. 100 en lysine et tryptophane et de 21 p. 100 en méthionine.

Les teneurs réduites du caséinate de sodium en ces acides aminés sont probablement dues au fait que ce n'est que la caséine de lait qui est dégagée au cours de la fabrication de cette prépara. tion, ainsi qu'aux conditions drastiques qui en accompagnent la dissolution. La caséine desséchée étant bien difficile à dissoudre et surtout dans la période initiale, on applique, au cours de ce procédé, une température et une concentration élevée en ions d'hydrogène et d'oxygène $\left(90^{\circ} \mathrm{C}-95^{\circ} \mathrm{C}, \mathrm{pH} 8,5-9,5\right)$.

Nos suggestions sont confirmées par les travaux de Myszkowska et Pijanowski ou bien par ceux de De Groot et Slump $[7,12]$ qui ont constaté que les protéines qui étaient retenues dans un milieu alcalin à une température élevée subissaient une réduction de leur valeur biologique ainsi que la diminution de leur teneur en certains acides aminés exogènes, et surtout en celle de lysine, méthionine, cystine et tryptophane.

La teneur élevée des protéinates obtenus, en acides aminés exogènes est due au fait que, non seulement la caséine mais aussi des protéines de lactosérum sont utilisées pour leur production. Ces derniers font augmenter d'une manière considérable le taux des acides aminés en question dans le produit fini. Outre cela, au cours de la fabrication des protéinates, des protéines sont dissoutes à une température bien moins élevée $\left(70^{\circ} \mathrm{C}-75^{\circ} \mathrm{C}\right)$ et, en même temps, la réaction du milieu ne dépasse pas la valeur de $\mathrm{pH}$ 6,8.

L'indice d'un acide aminé qui limite la cotation chimique (Chemical score) des protéines concentrées diverses a été calculé par Mitchel et Bloch [15]. Des valeurs ont été obtenues qui indiquaient que c'était la valine qui limitait la valeur biologique de la plupart des concentrés étudiés (fig. 1). La cystine et la méthionine (acides aminés sulfuriques) jouaient le même rôle pour le caséinate de sodium, tandis que la phénylalanine limitait partiellement le protéinate de sodium.

On a également constaté que les protéines concentrées diverses différaient par leur teneur en vitamines du groupe $B$, le caséinate de sodium ayant la teneur la moins élevée en chaque vitamine déterminée (fig. 2). La teneur en vitamines du groupe B était presque égale à celle de la caillebotte maigre [13] et un peu plus élevée que celle du lait en poudre [6]. C'est surtout la teneur élevée en vitamine $\mathrm{B}_{2}$ qui mérite un intérêt particulier (fig. 2). Les protéinates fabriqués présentaient une teneur en cette vitamine plus de deux fois plus élevée que celle de l'isolat de la protéine de soja qui, de l'avis des 


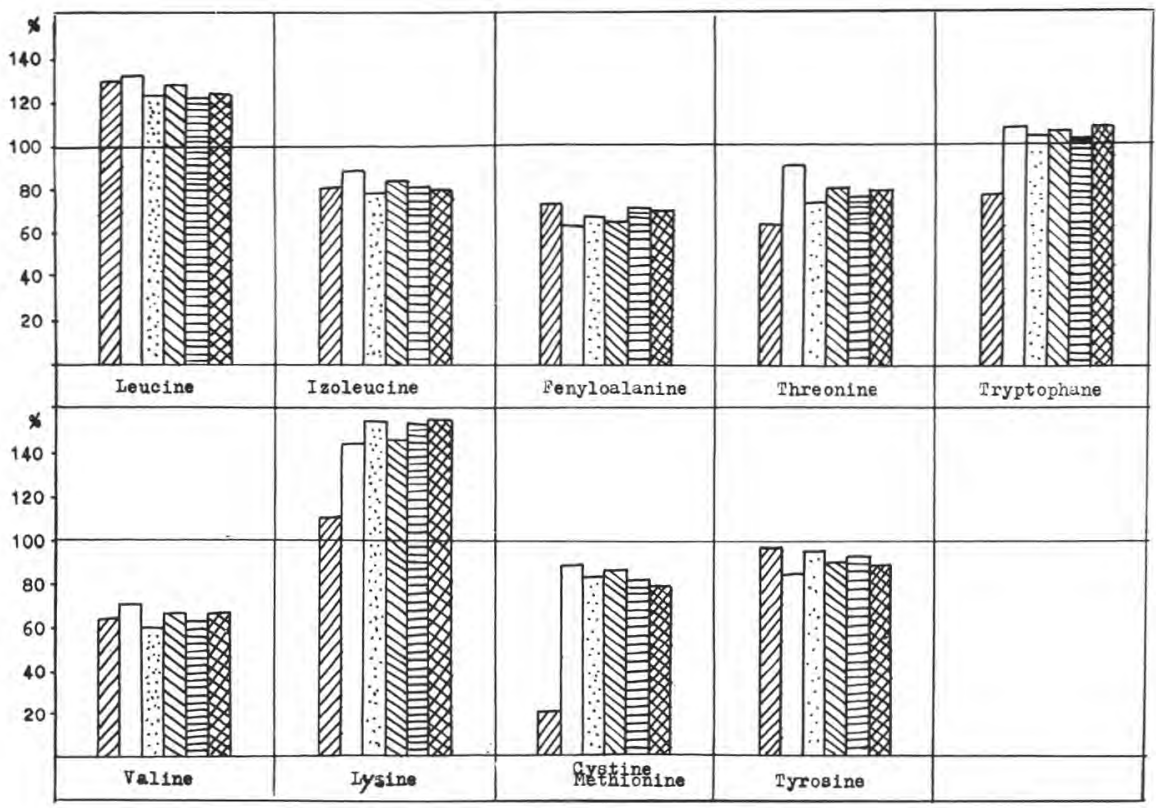

fig. 1

Teneur en acides aminés nécessaires des protéines concentrées, exprimée en pourcentage de la teneur en l'acide aminé en question du glaire d'œuf de poule, considérée comme 100 p. 100 [15].

WD caséinate de sodium.

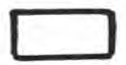

protéinate de sodium.

$\because \therefore:$ protéinate de calcium.
01 protéinate de sodium et calcium.



protéinate d'ammonium.

concentré de protéines de lait

事 n'ayant pas subi de traitement alcalin.

producteurs, est caractérisée par une teneur élevée en vitamines du groupe B [8]. En comparant leur teneur en ces vitamines avec celle des muscles frais de boeuf, on peut constater que l'introduction des protéines concentrées de lait aux produits de viande n'en fera pas trop diminuer la teneur en vitamines du groupe B. La teneur en vitamine $\mathrm{B}_{1}$ de la viande de bœuf est de $70-100 \mu \mathrm{g} / 100 \mathrm{~g}$, tandis que celle des protéines concentrées de lait est de 70-130 $\mu \mathrm{g} / 100 \mathrm{~g}$. Les chiffres correspondants pour la teneur en vitamine $\mathrm{B}_{2}$ sont : $150 \mu \mathrm{g} /$ $100 \mathrm{~g}$ et $850-1000 \mu \mathrm{g} / 100 \mathrm{~g}$; pour celle en vitamine $\mathrm{B}_{\mathrm{s}}: 350 \mu \mathrm{g} / 100 \mathrm{~g}$ environ et 150-210 $\mu \mathrm{g} / 100 \mathrm{~g}$; pour l'acide nicotinique : $4500 \mu \mathrm{g} / 100 \mathrm{~g}$ et $360-1000 \mu \mathrm{g} / 100 \mathrm{~g}$. 


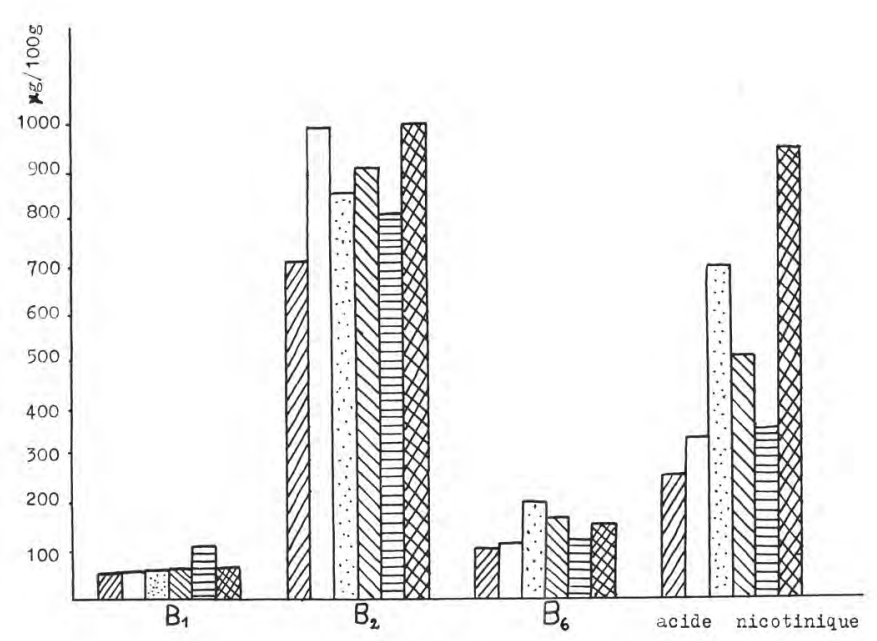

fig. 2

Teneur en vitamines du groupe B des protéines concentrées de lait

caséinate de sodium.

$\$$ protéinate de sodium et calcium.

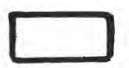

protéinate de sodium.

$\because \because \therefore$

protéinate de calcium.

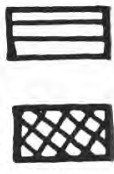

protéinate d'ammonium.

concentré de protéines de lait n'ayant pas subi de traitement alcalin.

La valeur biologique élevée des protéines concentrées mérite de même quelque intérêt (tab. 2). La valeur NPU variait pour des concentrés divers de 69,2 à 74,4, c'est-à-dire qu'elle était bien proche du coefficient de l'utilisation protéique pour le lait en poudre, séché par atomisation [19]. La valeur du coefficient d'utilisation protéique, déterminée pour le caséinate de sodium, était en moyenne de 20 unités moins élevée que celle du coefficient NPU des protéines concentrées qui avaient été obtenues de toutes les protéines de lait. $\mathrm{La}$ valeur NPU des protéines du caséinate de sodium était même moins élevée que celle de la caséine témoin, ce qui indique que la valeur biologique des protéines de caséinate de sodium a été diminuée en raison des techniques drastiques qui étaient employées dans le procédé de dissolution de la caséine $(\mathrm{pH}$ et températures trop élevés). 


\section{TABLEAU 2}

Valeur biologique des protéines concentrées de lait, exprimée par le coefficient d'utilisation des protéines (NPU)

\begin{tabular}{|c|c|c|c|c|}
\hline \multirow{2}{*}{ Sorte de concentré } & \multicolumn{4}{|c|}{ Valeur NPU des protéines } \\
\hline & $\begin{array}{l}\text { de deux } \\
\text { séries }\end{array}$ & $\begin{array}{l}\text { Différence } \\
\text { absolue }\end{array}$ & $\begin{array}{l}\text { Différence } \\
\text { relative }\end{array}$ & Moyenne \\
\hline Caséinate de sodium & $\begin{array}{l}51,5 \\
52,5\end{array}$ & 1,0 & 1,9 & 52,0 \\
\hline Protéinate de sodium & $\begin{array}{l}70,8 \\
73,6\end{array}$ & 2,8 & 3,9 & 72,2 \\
\hline Protéinate de calcium & $\begin{array}{l}72,4 \\
74,3\end{array}$ & 1,9 & 2,6 & 73,4 \\
\hline Protéinate de sodium et calcium & $\begin{array}{l}69,8 \\
71,0\end{array}$ & 1,2 & 1,7 & 70,4 \\
\hline Protéinate d'ammonium & $\begin{array}{l}73,2 \\
76,1\end{array}$ & 2,9 & 3,9 & 74,7 \\
\hline $\begin{array}{l}\text { Concentré de protéines de lait } \\
\text { n'ayant pas subi de traitement } \\
\text { alcalin }\end{array}$ & $\begin{array}{l}68,2 \\
70,2\end{array}$ & 2,0 & 2,9 & 69,2 \\
\hline Caséine témoin & $\begin{array}{l}59,7 \\
61,3\end{array}$ & 1,6 & 2,6 & 60.5 \\
\hline
\end{tabular}

Nous disposons de données, non publiées encore, qui démontrent que tout produit de protéine obtenu par nous de toutes les protéines de lait, révèle un coefficient PER extrêmement élevé : 3,4 environ, par comparaison à 2 pour la caséine et 2,5 pour les protéines de fromage fabriqué par le procédé traditionnel.

En comparant la composition en acides aminés, la teneur en vitamines du groupe B et la valeur biologique des protéines concentrées de lait, que nous avons produites, on peut constater que ces valeurs dépendent avant tout d'un degré d'utilisation des protéines de lait (c'est-à-dire de la caséine et des protéines de lactosérum) au cours de la fabrication de ces concentrés, ainsi que de la technique de transformation des protéines. 


\section{Rés u m é}

Nous avons déterminé la valeur biologique de protéines (NPU), la composition en acides aminés et la teneur en vitamines du groupe B de concentrés solubles des protéines du lait. Nous avons démontré que la valeur nutritive des protéines concentrées dépendait du degré d'utilisation de toutes les protéines de lait, ainsi que des valeurs de $\mathrm{pH}$ et des températures employées au cours de la conversion des protéines en forme soluble.

\section{S u $\mathbf{m} \mathbf{m}$ a r y}

Biological values of protein (NPU), amino acid composition and vitamin B contents were determined in solubles concentrates of milk proteins. It was shown that the nutritive value of protein concentrates depended on an extent to which all milk proteins were utilized, as well as on $\mathrm{pH}$ values and temperatures as used while converting proteins into soluble form.

Reçu pour publication en février 1976.

\section{Bibliographie}

[1] Арамiк (K.) (1968). - Kazeina i kazeiniany. Przeglad Mleczarski, 17, 18 et $17,17$.

[2] Borst (J. R.) (1971). - Milk proteins for use in the food industry. Food Technol. Austr., 23, 544.

[3] Buchanan (R. A.) (1967). - Caseins and caseinates. Dairy Industries, 32, 594.

[4] Buchanan (R. A.) (1970). - Dairy products in other food industry. Milk Ind., 67, 38.

[5] Chojnowski (W.) et al. (1975). - Characterization of concentrates of all milk proteins. Milchwissenschaft, 30, 407.

[6] Ford (J. E.), Kon (S. K.) and THOMPSON (S. Y.) (1958). - Effects of procesing on vitamins of the $\beta$-complex in milk. XV Int. Dairy Congr., 1, 429.

[7] De Groot (A. B.), Slump (P.) (1969). - Effects of severe alkali treatment of proteins on amino acid composition and nutritive value. J. Nutrition, 98, 45.

[8] Kellor (R. L.) (1974). - Defatted soy flour and grits. J. Am. Oil. Chem., $15,77$.

[9] Kunachowicz (H.), Grabarek (Z.), Szkilladziowa (W.) (1974). - Charakterystyka wartosci odzywczej bialek preparatow bialkowych. Roczniki PZH, 25, 171.

[10] Miller (D. S.), Bender (A. E.) (1955). - The determination of the net utilization of proteins by a shortened method. Brit. J. Nutr., 12, 382.

[11] Moor (S.), Spackman (D. H.), Stein (W. H.) (1958). - Chromatography of amino acids on sulphoneted polystyrene reins. Anal. Chem., 30, 1185.

[12] Myszkowska (K.), Pijanowski (E.) (1971), - Effects of alkaline treatment on the nutritive value of casein food products. Protectio Vitae, 1, 127. 
[13] PIJanowski (E.) (1971). - Zarys chemii i technologii mleczarstwa, T.I, Mleko surowe, spozywcze i konserwy mleczne. PWRiL, Warszawa.

[14] Poznanski (S.) et al. (1973). - Sposob produkcji rozpusczcalnych bialek mleka w proszku. Patent PRL Nr.

[15] Rakowska (M.) Kunachowicz (H.), Szkilladziowa (W.) (1971). - Ocena wartosci odzywczej bialek i mozliwosci wzajemnego uzupelniania sie produktow spozywczych na podstawie zawartosci aminokwasow egzogennych. Przemysl Spoz., 25, 114.

[16] RAFALSKI (H.) (1973). - Biologiczna jakosc bialek produktow spozywczych po obrobce technologicznej. Przemysl Spoz., 27, 424.

[17] Secomska (B.) (1973). - Wplyw obrobki technologicznej na zachowanie witamin rozpuszczalnych w wodzie. Przemysl Spoz., 27, 394.

[18] Szkilladziowa (W.), Kunachowicz (H.) (1973). - Wplyw obrobki technologicznej zywnosci na wartosc odzywcza bialka. Przemysl Spoz, 27, 414.

[19] SzKILladziowa (W.) et al. (1970). - Badania wartosci odzywczej krajowego mleka w proszku. Wplyw ogrzewania mleka na strawnosc i wykorzystanie jego bialka. Przem. Spoz., 2٪, 7.

[20] Wituszynska (B.) (1968). - Oznaczanie witamin z grupy B w produktach rybnych. Zesz. Gdanskiego Tow. Nauk., 5, 171.

[21] Zoltowska (A.), BaLicki (B.) (1971). - Dodatki bialkowe i charakterystyka ich przydatnosci w przetwerstwie miesnym. Gosp. Miesne, 23, 7. 